\title{
Contribuições do governo eletrônico para a reforma administrativa e a governança no Brasil
}

Paulo Henrique Ramos Medeiros

e Tomás de Aquino Guimarães

\section{Introdução}

Os governos de distintos países operam num mundo complexo e precisam adaptar-se a novas realidades, como a globalização e a sociedade da informação, contexto em que as tecnologias de informação e comunicação (TICs) têm papel crucial no modo como o Estado cumpre suas principais funções.

Essas tecnologias mudam a abordagem da gestão pública e o governo eletrônico vem-se mostrando como uma das maneiras encontradas pelo setor público para prestar seus serviços de modo a atender, mais ágil e eficientemente, às demandas da sociedade. Identificado como inovação em administração, o e-gov representa, essencialmente, o provimento de acesso, via Internet, a informações e serviços oferecidos pelos governos.

Com a evolução do uso de computadores, dos meios de comunicação e, especialmente, da infra-estrutura da Internet, definiram-se novas formas para os modelos de relacionamento Estado-sociedade, cada vez mais baseados em TIC. 
Nesse ambiente em que as reformas administrativas vêm sendo desencadeadas pelos governos, a chamada Nova Administração Pública (BARZELAY, 2001) tem apontado o uso das TICs como uma das ferramentas de gestão mais eficazes para o incremento $\mathrm{da}$ governança, em termos da informatização de serviços e da conseqüente aproximação com o cidadão.

Tendo em vista o contexto apresentado, o presente artigo tem como objetivo identificar alguns possíveis resultados trazidos pelo governo eletrônico para a reforma administrativa e a governança no Brasil.

Com relação à governança, o avanço de novas tecnologias nas décadas recentes incentiva o estudo do possível impacto provocado por essas inovações na maneira como o Estado presta seus serviços, bem como na própria gestão administrativa do aparelho estatal.

Além disso, estudos empíricos apresentados por Heeks (2002) mostram que as TICs vêm tendo papel crescentemente importante quando se fala em iniciativas de reforma no setor público, o que justifica o presente estudo, pois aumenta o conhecimento sobre o papel do governo eletrônico nas reformas realizadas na administração pública brasileira nos anos recentes.

\section{Governo eletrônico}

O advento da Internet e as inovações tecnológicas em comunicações proporcionaram às organizações a possibilidade de migrarem seus sistemas existentes em plataformas convencionais para sistemas com interface web. Entre os principais aspectos que incentivaram o surgimento dessa inovação, podem ser citados, pela ordem de relevância para os governos: 1) a necessidade de as administrações aumentarem sua arrecadação e melhorarem seus processos internos; e 2) as pressões da sociedade para que o governo otimizasse seus gastos e atuasse, cada vez mais, com transparência, qualidade e de modo universal na oferta de serviços aos cidadãos e às organizações em geral.

As possibilidades de otimização de processos de governo baseados em soluções de TIC passam por princípios definidos pelos conceitos de governo eletrônico. Portanto, para que se tenha idéia clara do objeto deste estudo, procurou-se, a partir de revisão bibliográfica e documental, investigar quais seriam as definições mais utilizadas para caracterizar o governo eletrônico, chegando-se a algumas delas, como as apresentadas no Quadro 1.

\section{O contexto brasileiro}

Pode-se descrever o início do governo eletrônico no Brasil a partir do breve histórico apresentado a seguir (SouzA, 2002, p. 33):

"Por intermédio do Decreto Presidencial de 3 de abril de 2000, criou-se um Grupo de Trabalho Interministerial, com a finalidade de examinar e propor políticas, diretrizes e normas relacionadas com as novas formas eletrônicas de interação. Informalmente, esse núcleo de pessoas ficou conhecido como Grupo de Trabalho em Tecnologia da Informação (GTTI). A criação do GT'TI foi inserida dentro da política do Governo, para lançar as bases da criação de uma sociedade digital no Brasil. Suas ações coadunaram-se com as metas do Programa Sociedade da Informação [SocInfo], coordenado pelo Ministério da Ciência e Tecnologia (MCT). Nesse contexto, o GTTI assumiu o papel de 
Quadro 1: Definições de governo eletrônico

\begin{tabular}{|l|l|}
\hline Definição & Fonte \\
\hline $\begin{array}{l}\text { Governo eletrônico ou e-governo significa prover acesso } \\
\text { público, via Internet, a informações sobre os serviços } \\
\text { oferecidos pelos departamentos centrais do governo e pelas } \\
\text { suas agências, habilitando o público à condução e conclusão } \\
\text { de transações para tais serviços. }\end{array}$ & $\begin{array}{l}\text { National Audit } \\
\text { Office (2002a, p.1) }\end{array}$ \\
\hline $\begin{array}{l}\text { O termo “e-government" [utilizado em inglês para denominar } \\
\text { o governo eletrônico] aborda o uso de novas tecnologias de } \\
\text { informação e comunicação pelos governos, aplicadas a todas } \\
\text { as suas funções. }\end{array}$ & OCDE (2001, p. 2) \\
\hline $\begin{array}{l}\text { E-governo é definido como: utilização da Internet e } \\
\text { da web para ofertar informações e serviços governamentais } \\
\text { aos cidadãos. }\end{array}$ & $\begin{array}{l}\text { Nações Unidas } \\
\text { (2002, p. 1) }\end{array}$ \\
\hline $\begin{array}{l}\text { Governo eletrônico refere-se a processos e estruturas } \\
\text { relativos ao fornecimento eletrônico de serviços } \\
\text { governamentais ao público. }\end{array}$ & $\begin{array}{l}\text { Okot-Uma } \\
\text { (2001, p. 9) }\end{array}$ \\
\hline
\end{tabular}

Fonte: Referências mencionadas no quadro.

facilitador na busca dos objetivos daquele Programa”.

Com a criação do Comitê Executivo do Governo Eletrônico (Cege), em outubro de 2000 , foram definidos papéis a serem cumpridos por diversos órgãos públicos e foram implementadas ações e normas que conformaram o ambiente institucional em que o e-gov se estabeleceu no País. Em 2003, foram criados oito comitês técnicos no âmbito do Cege, com a finalidade de coordenar e articular o planejamento e a implementação de projetos e ações nas respectivas áreas de competência.

O arranjo institucional do governo eletrônico no País, no âmbito do poder público, pode ser descrito da seguinte forma (BRASIL, 2002b, p. 15):

"O Programa Governo Eletrônico tem sido implementado com base na atuação coordenadora e mobilizadora, empreendida a partir da Presidência da
República, com apoio técnico e gerencial da Secretaria de Logística e Tecnologia da Informação (SLTI), do Ministério do Planejamento, Orçamento e Gestão (MP). A SLTI é responsável pelo planejamento estratégico, coordenação interministerial e emissão de normas relacionadas com a área de informática. [...].

Essa atuação está sustentada em comitê integrado pelos secretáriosexecutivos (e cargos equivalentes) dos ministérios e órgãos da Presidência da República, denominado Comitê Executivo de Governo Eletrônico [...]”.

No Brasil, os projetos de e-gov dos demais entes federativos têm sido estimulados pelo progresso das iniciativas do governo federal, desenvolvidas em duas vertentes de atuação básicas (que, por vezes, se sobrepõem): 1) nas diretrizes do Comitê Executivo do Governo Eletrônico, 
executadas por meio do Programa Governo Eletrônico e outros programas governamentais; e 2) em três das sete linhas de ação do Programa SocInfo - "Universalização de serviços para a cidadania", "Governo ao alcance de todos" e "Infraestrutura avançada e novos serviços".

\section{Reforma administrativa}

A crise fiscal, à qual se seguiram movimentos de reforma administrativa, e o advento da sociedade da informação forçaram os governos a procurar novas formas de melhorar a prestação de seus serviços, e uma das respostas encontradas foi o uso de tecnologias para tornar a atuação de suas unidades menos dispendiosa e capaz de fornecer respostas mais ágeis aos usuários de serviços públicos. As teorias da Nova Administração Pública abordam - entre muitos outros aspectos - essa temática.

A expressão "Nova Administração Pública” (NAP) (New Public Management, em inglês) apareceu inicialmente no início dos anos 90, como resultado de investigação acadêmica em países anglo-saxões, especialmente Reino Unido, Austrália e Nova Zelândia, acerca de novos temas, estilos e padrões inseridos na administração pública desses países a partir da década de 80 (BARZELAY, 2001). A NAP é definida por Barzelay (2000, p. 230) como "um campo de discussão profissional e de políticas conduzido internacionalmente - sobre assuntos relacionados à gestão pública, incluindo gestão de políticas públicas, liderança executiva, projeto de organizações programáticas e operações de governo”.

Quanto ao alinhamento do governo eletrônico a iniciativas de reforma da administração pública, nota-se que as chances de transformação (mudança) com sucesso são maiores quando o e-gov faz parte de contexto maior, enraizado em uma política global de reforma administrativa, tendo em vista que as "mudanças em sistemas de informação têm sido sempre uma parte essencial de toda mudança organizacional no governo" (HEEks, 2002, p. 20).

No Brasil, a referência em relação à última reforma ocorreu com a elaboração do documento intitulado Plano diretor da reforma do aparelho do Estado (BRASIL, 1995). A proposta básica do plano era "transformar a administração pública brasileira de burocrática em gerencial” (BREsSER Pereira, 1998, p. 22). Esse novo modelo de administração - o gerencialismo - teria como uma de suas características básicas a inovação e seria resultado de uma reforma do Estado que envolveria aspectos políticos, econômicos e administrativos. Estes últimos visariam ao aumento da governança. A reforma administrativa seria capaz de criar, portanto, "os meios de se obter uma boa governança” (BRESSER Pereira, 1998, p. 36).

Apesar de não ter sido o principal propulsor da implementação de novas ferramentas de gestão baseadas nas TICs, o plano diretor fez uma abordagem embrionária da questão, ao reservar dois tópicos em seu Capítulo 8, relacionados ao objeto desta pesquisa. Num desses tópicos, 8.2.9 - "Sistemas de gestão pública", o plano aborda aspectos relacionados: 1) à implementação de sistemas capazes de oferecer transparência às ações do governo federal; 2) à disponibilização de informações gerenciais aos gestores públicos, de modo a facilitar a tomada de decisões; e 3) ao acesso facilitado aos cidadãos de dados disponíveis nos sistemas de informação do governo, "por vários meios (com ênfase em sistemas 
de fácil acesso, como a Internet)" (BRAsIL, 1995, p. 67).

O próprio governo federal veio a reconhecer, entretanto, anos após a proposta do plano diretor para assuntos relacionados às TICs, que, "nas suas origens, a reforma administrativa no Brasil conviveu com um estágio pouco evoluído da tecnologia da informação e comunicação. Em especial, desconhecia-se o potencial de realização de transações de toda ordem, em escala global e a custos reduzidos, representado pelo advento da Internet" (BRASIL, 2002b, p. 4).

\section{Governança}

Governança é um termo sem definição única, tendo sido caracterizado de maneiras diferentes por organismos internacionais, como o Ministério do Desenvolvimento Internacional do Reino Unido (Department for International Development - DFID), o Programa das Nações Unidas para o Desenvolvimento (PNUD) e o Banco Mundial, os quais difundiram o conceito e despertaram o interesse acadêmico em torno do tema. Sua definição mais abrangente indicaria algo como uma ampla estratégia de reforma para reforçar as instituições da sociedade civil e tornar os governos mais abertos, responsáveis, transparentes e democráticos.

Lane (2000) define a governança aplicada ao setor público como um conjunto de teorias sobre como os governos se articulam para o provimento de serviços em uma sociedade. Melo (1996), por sua vez, em estudo que relacionou a temática da reforma do Estado com o conceito de governança, fez ampla análise sobre as diversas possibilidades de se defini-la. Distinta da governabilidade conceituada como "as condições sistêmicas de exercício do poder em um sistema político” (Melo, 1996, p. 68-69) -, a governança implicaria o modo de uso da autoridade política e estaria relacionada à "capacidade governamental de criar e assegurar a prevalência [...] de regras universalistas nas transações sociais, políticosociais e econômicas" (Melo, 1996, p. 69).

No setor público, o conceito normalmente está relacionado à habilidade e capacidade de o poder público imple-

“O governo

eletrônico não pode

ser visto como panacéia

para as reformas

administrativas:

o uso de tecnologias

deve caminhar em

paralelo com outras

medidas ou mesmo em

reforço a uma mudança

cultural, funcionando

as TICs, na verdade,

como catalisadoras

de inovações"

mentar, de forma efetiva, suas políticas, previamente planejadas. Neste trabalho, será utilizada esta última definição, somandose a ela, entretanto, a importância dos arranjos institucionais em parceria com os demais atores sociais, além do marco legal, para que o Estado consiga, de fato, alcançar ambiente favorável à governança.

Essa relação entre agentes institucionais, que contribui para o entendimento da 
governança, sofreu grandes mudanças com o advento das redes de computadores, especialmente a Internet, o que causou mudanças profundas no modo como as redes interorganizacionais ou policy networks - transações, fluxos e ligações relativamente resistentes que ocorrem entre organizações - passaram a operar, inclusive com reflexos na estrutura do Estado e no processo de formulação de políticas públicas (Fountain, 2001).

Frey (2000, p. 11-12) explica que as redes interorganizacionais seriam redes sociais formadas em torno de políticas específicas e ressalta a importância do conceito para a análise de políticas públicas, "sobretudo enquanto (sic) fatores dos processos de conflito e de coalizão na vida políticoadministrativa". Essas redes de atores formadas por agências de governo, além dos setores privado e não governamental (terceiro setor), são "mais centrais à formulação das políticas do que somente estruturas formalizadas de governança" (Fountain, 2001, p. 66).

\section{Métodos e procedimentos}

A pesquisa englobou o período de 2000 a 2003, considerando que "a formulação de uma política de tecnologia da informação e comunicação voltada para a administração pública teve seu marco inicial na elaboração de documento que definiu diretrizes, objetivos e metas até 2003" (Brasil, 2002a, p. 1), intitulado Proposta de política de governo eletrônico para o Poder Executivo federal (BRAsIL, 2000), lançado em setembro de 2000.

Para este trabalho, foram realizadas as seguintes pesquisas:

1) bibliográfica: revisão da literatura em livros, periódicos, dissertações de mestrado, teses de doutorado e anais de congressos científicos;
2) documental: documentos gerados pelo Cege; Livro Verde, do Programa Sociedade da Informação, orçamentos da União no período de 2000 a 2003 e Plano Plurianual 2000-2003;

3) de campo: coleta de dados primários por meio de entrevistas semi-estruturadas;

4) em instrumentos e ações executadas pelo governo federal: formulação de políticas de governo eletrônico a cargo do Cege; iniciativas planejadas e executadas no governo federal em relação ao governo eletrônico, no período de 2000 a 2003, e observação de portais do governo federal na Internet.

Os stakeholders entrevistados foram agrupados nos seguintes tipos, identificados neste artigo como "agentes [ou atores] institucionais" do ambiente do governo eletrônico, conforme o Quadro 2: 1) gestores públicos (setor público), 2) empresários e consultores (iniciativa privada), 3) dirigentes de organizações não governamentais - ONGs (terceiro setor) e 4) professores universitários (academia). A seleção dos entrevistados foi feita a partir da análise das atribuições de seus cargos em nível estratégico ou gerencial - e de seu grau de atuação em relação às ações do Poder Executivo federal relacionadas ao e-gov.

Para a realização da coleta de dados, foram utilizados roteiros de entrevistas semi-estruturadas para um único respondente por vez - entrevistas em profundidade -, com perguntas abertas. Os roteiros de entrevistas foram aplicados a 27 informantes-chave, conforme apresentados no Quadro 2, de setembro a dezembro de 2003.

Devido à grande quantidade de dados e à complexidade das interações de opiniões dos quatro diferentes grupos de entrevistados, foi utilizado, para auxílio à análise de conteúdo e à ordenação 
Quadro 2: Relação de entrevistados por setor institucional

\begin{tabular}{|c|c|c|}
\hline Setor & Organização & $\begin{array}{l}\text { Entrevistados } \\
\text { por Organização }\end{array}$ \\
\hline \multirow{6}{*}{ Setor Público } & Instituto Nacional de Tecnologia da Informação (ITI) & 1 \\
\hline & $\begin{array}{l}\text { Programa Governo Eletrônico/Serviço de } \\
\text { Atendimento ao Cidadão (Gesac)/Ministério } \\
\text { das Comunicações }\end{array}$ & 1 \\
\hline & $\begin{array}{l}\text { Programa Sociedade da Informação (SocInfo)/ } \\
\text { Ministério da Ciência e Tecnologia }\end{array}$ & 1 \\
\hline & $\begin{array}{l}\text { Secretaria de Logística e Tecnologia da Informação / } \\
\text { Ministério do Planejamento, Orçamento e Gestão } \\
\text { (SLTI/MPOG) }\end{array}$ & 6 \\
\hline & Serviço Federal de Processamento de Dados (Serpro) & 1 \\
\hline & Tribunal de Contas da União (TCU) & 2 \\
\hline \multicolumn{2}{|r|}{ Total de entrevistados do setor } & 12 \\
\hline \multirow{4}{*}{$\begin{array}{l}\text { Iniciativa } \\
\text { Privada }\end{array}$} & Accenture & 2 \\
\hline & Cisco Brasil & 1 \\
\hline & Conectiva & 1 \\
\hline & Politec & 1 \\
\hline \multicolumn{2}{|r|}{ Total de entrevistados do setor } & 5 \\
\hline \multirow{6}{*}{$\begin{array}{l}\text { Terceiro } \\
\text { Setor }\end{array}$} & Agência Eletrônica & 1 \\
\hline & $\begin{array}{l}\text { Comitê para Democratização da Informática do } \\
\text { Distrito Federal e Entorno (CDI-DF) }\end{array}$ & 1 \\
\hline & $\begin{array}{l}\text { Escola do Futuro - Centro de Inclusão Digital e } \\
\text { Educação Comunitária (CIDEC) - Universidade } \\
\text { de São Paulo (USP) }\end{array}$ & 1 \\
\hline & $\begin{array}{l}\text { Instituto Euvaldo Lodi (IEL) - Federação das } \\
\text { Indústrias do Estado do Rio de Janeiro (FIRJAN) }\end{array}$ & 1 \\
\hline & Projeto SAMPA.ORG & 1 \\
\hline & Rede de Informações para o Terceiro Setor (RITS) & 1 \\
\hline \multicolumn{2}{|r|}{ Total de entrevistados do setor } & 6 \\
\hline \multirow{4}{*}{ Academia } & $\begin{array}{l}\text { Escola Brasileira de Administração Pública e de } \\
\text { Empresas da Fundação Getúlio Vargas (EBAPE/FGV) }\end{array}$ & 1 \\
\hline & $\begin{array}{l}\text { Programa das Nações Unidas para o } \\
\text { Desenvolvimento (PNUD)London School } \\
\text { of Economics and Political Science (LSE) }\end{array}$ & 1 \\
\hline & Universidade de São Paulo (USP) & 1 \\
\hline & Universidade do Estado do Rio de Janeiro (UERJ) & 1 \\
\hline & Total de entrevistados do setor & 4 \\
\hline
\end{tabular}

Fonte: Elaboração do autor a partir de dados da pesquisa. 
conceitual, o software Atlas.ti, apropriado para análise qualitativa de informações obtidas por meio de entrevistas. As gravações das entrevistas foram feitas em formato digital, transcritas com a utilização de um processador de textos e, por fim, inseridas no software, num total de 513 páginas de texto.

$\mathrm{Na}$ fase da seleção de unidades de análise (citações), o Atlas.ti foi utilizado para classificar as falas dos entrevistados em torno de três códigos, originados da revisão bibliográfica: 1) reforma administrativa; 2) governança e 3) desenvolvimento econômico-social.

\section{Resultados e discussão}

Tendo em vista a utilização das falas dos entrevistados no decorrer da discussão, estabeleceu-se uma identificação dos informantes-chave por setor institucional a que pertencem, do seguinte modo: 1) setor público: prefixo $\mathrm{SP}$, numerados de 1 a 12 ; 2) iniciativa privada: prefixo IP, numerados de 1 a 5; 3 ) terceiro setor: prefixo TS, numerados de 1 a 6 ; e 4) setor acadêmico: prefixo $\mathrm{SA}$, numerados de 1 a 4 .

Ao serem mencionadas as falas dos entrevistados adiante, neste artigo, a identificação será feita como nos seguintes exemplos: entrevistado SP2, entrevistado IP5, entrevistado TS1, entrevistado SA3 e assim por diante. Ressalte-se que essa numeração não guarda qualquer relação com a ordem de apresentação das organizações do Quadro 2.

A investigação do código reforma administrativa no contexto do governo eletrônico está ligada ao que Heeks (2002) denomina, em termos gerais, de "reinvenção do governo na era da informação". Essa definição trata, na verdade, segundo esse autor, de continuação dos movimentos de reforma do Estado mais amplamente encontrados na literatura acadêmica, mas com ênfase maior em dois aspectos relativos aos processos de mudança: um papel maior para: 1) a informação e os sistemas de informação; e 2) a tecnologia da informação nos processos de mudança.

A modernização do aparelho de gestão pública por via das tecnologias de informação e comunicação (TICs), considerando o governo eletrônico como uma das políticas de gestão pública, foi vista pelos entrevistados como uma das mais profícuas ferramentas para serem empregadas nas iniciativas de mudança pelas quais o Estado está continuamente sendo submetido, conforme enfatizado pelo entrevistado SP11:

"Eu acho que há um certo consenso de que a máquina pública tem de ser "desenferrujada", tem de "rodar". E existe também um certo consenso de que a TI é um mecanismo real para se conseguir destravar essa máquina”.

O próprio entrevistado SP11 alerta, entretanto, que o e-gov não pode ser visto como panacéia para a reforma administrativa: "Eu acho que o programa de governo eletrônico pode solucionar uma gama de problemas. Mas não vai solucionar todos". Essa ressalva mostra que essa política deve caminhar paralelamente a outras medidas governamentais, nos campos político e econômico, por exemplo, ou mesmo como reforço a uma mudança cultural no interior do setor público, funcionando as TICs como catalisadoras de inovações.

O papel das tecnologias na reforma do aparelho estatal foi visto por diferentes ângulos pelos entrevistados, entre os quais são ressaltados os seguintes: 1) introdução 
de novo paradigma vinculado à sociedade da informação no modo de funcionamento do Estado; e 2) potencial de integração que as TICs podem proporcionar ao Estado, tanto internamente, para sua própria gestão, como externamente, em relação aos demais atores institucionais que com ele se relacionam.

Fernandes (2004, p. 108) argumenta que, mesmo com a mudança na gestão de governo a partir de 2003, "o e-gov se mantém como promissor eixo para a integração de um amplo leque de projetos e ações do governo federal". Por outro lado, embora acreditem que as TICs - e, portanto, a política de governo eletrônico - tenham um importante papel a desempenhar na reforma administrativa, os entrevistados entenderam que esse potencial não se encontra inserido com a devida ênfase na agenda governamental, conforme ilustra a opinião do entrevistado SA2:

"Não vejo o governo ainda se apropriando dessa discussão de sistemas, de gestão pública, de produtividade... Está se apropriando, sim, da discussão da dependência da área tecnológica, da importância de desenvolvimento. Esses fronts da questão vêm sendo enfrentados, mas os outros, mais ligados à área de reforma do Estado, ainda não...”.

As mudanças que o governo eletrônico pode trazer ao Estado foram vistas pelos entrevistados mais como alterações de processos do que como estrutura. A diferença de ênfases encontrada nas unidades de análise (citações) pode ser explicada a partir do entendimento que Grande, Araújo e Serna (2002, p. 14, grifo nosso) têm do e-gov, quando visualizado na ótica da Nova Administração Pública:
"A implementação do governo eletrônico à luz das características da NGP [Nova Gestão Pública] implica a necessidade de transformações na gestão e organização das administrações públicas. O governo eletrônico permite que a organização se fundamente no fluxo de informação [processos] mais que na hierarquia [estrutura], implica operações racionalizadas e menos

"As melhorias em processos proporcionadas pelo e-gov devem transpor duas barreiras: a dificuldade de integração de processos existentes em distintas unidades governa-mentais e a resistência cultural dos servidores públicos para o redesenho de processos"

operadores intermediários ou de base. [...] a flexibilidade organizativa gera uma ruptura das fronteiras organizativas, de modo a que os clientes não tenham que ser necessariamente conscientes dos limites precisos entre diferentes departamentos, dado o enfoque rumo à prestação de serviços". 
$\mathrm{Na}$ opinião dos entrevistados, as melhorias em processos proporcionadas pelo e-gov deveriam transpor duas barreiras, antes de serem usufruídas: 1) dificuldade de integração de processos existentes em distintas unidades governamentais; e 2) resistência cultural dos servidores públicos para o redesenho de processos. Quanto ao primeiro aspecto, os entrevistados entenderam que haveria a necessidade de, previamente à implementação de ações de integração de sistemas e bases de dados para a oferta de serviços na web, viabilizarem-se entendimentos entre as diversas organizações que geram os recursos de TI no setor público.

A resistência cultural do funcionalismo público é outra barreira a ser vencida pelo governo eletrônico, antes que processos inovadores possam contribuir com a modernização da gestão pública. Sobre o assunto, o entrevistado SP9 opinou da seguinte forma:

"O redesenho de processos é muito sofrido, duro, mexe com os 'pequenos poderes', com estruturas mentais arraigadas, com muita coisa que não tem nada a ver com TI. Tem a ver com o ser humano e podemos não estar à altura do desafio, espero que estejamos. Mas é uma tarefa que vai muito além dos gestores de um governo A com um mandato definido: implica que todos os gestores públicos assumam esse desafio."

O National Audit Office (NAO) (2002b), ao investigar o governo eletrônico, com auxílio do setor acadêmico britânico, explica essa barreira originada no setor público como uma espécie de "trauma" dos gestores públicos em implementar custosos projetos de TI - como os de e-gov -, tendo em vista a lembrança de fracassos anteriores: “[...] experiência prévia com projetos de TI que ultrapassaram seus orçamentos, trouxeram poucas economias ou mesmo falharam completamente pode levar à relutância em investir em tecnologias baseadas na web" (National Audit Office, 2002b, p. 3). Essa barreira foi considerada "irônica" pelo NAO (2002b, p. 3), pois as tecnologias web tendem a ser mais baratas e mais fáceis de serem desenvolvidas do que as tecnologias anteriores.

O código governança investigou os possíveis reflexos do governo eletrônico na governança, englobando o conceito em si e o programa federal de governo eletrônico. A análise contou, ainda, com o código desenvolvimento socioeconômico.

As opiniões dos entrevistados concentraram-se em três dimensões, quanto a esse potencial do e-gov: 1) ganhos em eficiência, transparência e controle; 2) melhor interação interna e externa ao governo com a utilização das TICs; e 3) governo eletrônico como política de gestão pública contribuindo com as demais políticas públicas. $\mathrm{O}$ primeiro dos aspectos mencionados foi expresso da seguinte forma pelo entrevistado SP2:

"O governo eletrônico tem o potencial de permitir uma melhoria extraordinária na eficiência, na integração da máquina administrativa e, indiretamente, tem um impacto importantíssimo na governança, conferindo fluidez à máquina administrativa. Faria as coisas funcionarem melhor, com mais rapidez, o que melhoraria o desempenho do governo federal e, por tabela, fortaleceria a capacidade de governança". 
As TICs que seriam incorporadas à gestão do governo por meio de projetos de e-governo poderiam facilitar, segundo os entrevistados, o planejamento, a comunicação e o fluxo de processos internos do governo, além da interação com os cidadãos, conforme ressaltado pelo entrevistado SP1:

“Tecnologias da informação e comunicação como um todo, para um país como o Brasil, geram um profundo impacto em governança, tanto em planejamento como em execução de atividades. A parte de planejamento é muito pouco explorada, no Brasil, é 'artesanal' e poderia ser muito mais incrementado".

Os entrevistados perceberam, ainda, que o governo eletrônico pode contribuir com a governança em seu papel de facilitador das demais políticas públicas, ao incrementar a gestão pública com o auxílio das tecnologias. $O$ atual estágio de utilização das TICs nas organizações, inclusive as públicas, e a complexidade na interação entre as diversas políticas públicas mostram que o e-governo é uma política essencial para a gestão do aparelho estatal, daí sua contribuição à governança.

Embora tenha sido reconhecido pelos entrevistados o potencial do e-gov para o incremento da governança, houve a ressalva de que o estágio atual de emprego desse potencial ainda seria incipiente no Brasil: "A contribuição do e-gov para a governança ainda pode ser muitíssimo melhorada" (SP3).

Foi destacada a possibilidade de o governo eletrônico contribuir para o desenvolvimento socioeconômico do País, o que traria reflexos positivos à governança. Os entrevistados acreditam que as TICs podem trazer dividendos à governança, caso o País seja capaz de implementar políticas que aproveitem esse potencial, conforme manifestação, por exemplo, do entrevistado SP6:

"As chamadas TICs são tão importantes hoje para um país como o Brasil que poderíamos dar um salto e pular anos de atraso, o que requereria, na verdade, um status de ministério, recursos próprios, incentivos próprios, concentrando o foco. O desenvolvimento seria mais rápido, daríamos um fôlego muito maior às indústrias de TI no País".

A opinião prevalecente, portanto, foi a de que há um enorme potencial ainda a ser explorado para que o governo eletrônico brasileiro tenha reflexos na governança do Estado. Essa percepção dos entrevistados deve ser ponderada, considerandose o fato de que o emprego de tecnologias é apenas um dos muitos aspectos que podem impactar a ação coletiva e o papel dos governos.

\section{Conclusão}

As TICs foram vistas como a principal ferramenta para as iniciativas de modernização do Estado, especialmente pelo potencial do e-gov como política de gestão pública capaz de aprimorar o desempenho das demais políticas governamentais.

A reforma administrativa seria um tema que só teria sentido na sociedade da informação com a utilização de tecnologias para o alcance de seus objetivos, pois quaisquer mudanças na gestão implicariam o redesenho de sistemas de informação: "quer seja reconhecido ou não pelos stakeholders, são os sistemas de informação que são centrais aos processos de 
reforma na era da informação" (HeEks; Bhatnagar, 2002, p. 49).

Fernandes (2004, p. 102) vê, de modo positivo, essas possibilidades de se empregar o e-governo para a transformação da administração pública, ao afirmar que, "de forma geral, as concepções, os modelos, as tecnologias e os instrumentos associados ao e-gov são capazes de potencializar a aplicação das principais diretrizes que norteiam os intentos da reforma".

Chegou-se à conclusão, entretanto, que o governo eletrônico não pode ser visto como panacéia para as reformas administrativas: o uso de tecnologias deve caminhar paralelamente com outras medidas governamentais, nos campos político e econômico, por exemplo, ou mesmo em reforço a uma mudança cultural no próprio setor público, funcionando as TICs, na verdade, como catalisadoras de inovações.

Não obstante as considerações feitas neste artigo sobre as possíveis contribuições do e-gov para a reforma administrativa, deve-se levar em conta que a possibilidade de se perceber essa influência é restrita no presente trabalho, tendo em vista o curto espaço de tempo transcorrido desde a implementação dessa política no País, especialmente a partir do ano 2000 (criação do Comitê Executivo do Governo Eletrônico). Uma percepção mais próxima da realidade só será possível após o transcurso de prazo razoavelmente longo para que se possam avaliar a história institucional da política, seus resultados pragmáticos e, finalmente, sua influência na gestão do aparelho do Estado.

Quanto à governança, o governo eletrônico foi visto como uma das maneiras mais eficientes para aprimorá-la, especialmente nas seguintes áreas: 1) ganhos em eficiência, transparência e controle do aparelho estatal; 2) melhor interação interna e externa ao governo com a utilização das TICs - o que mostra a importância das redes interorganizacionais; e 3) governo eletrônico como política de gestão pública para o incremento das demais políticas públicas.

Chegou-se à conclusão, ainda, de que o e-gov pode ser um dos caminhos para incrementar a governança - o estágio dessa contribuição é ainda incipiente no Brasil , se a política for capaz de auxiliar no desenvolvimento socioeconômico do País. $\mathrm{O}$ aspecto econômico poderia ser percebido pela maior eficiência do governo redução de custos e eliminação de desperdícios -, bem como pela influência, por exemplo, na política de tecnologia da informação do País, abrindo mercados à exportação e desenvolvendo tecnologia em nível local.

O desenvolvimento social pode ser visualizado pelo aumento do conhecimento proporcionado por maior acesso às TICs, especialmente a Internet. De modo nada surpreendente, estudos comparativos entre diferentes países mostram que "a maturidade do e-governo tende a refletir o nível de desenvolvimento econômico, social e democrático de uma nação" (Intosai, 2003, p. 6).

O e-governo não pode, entretanto, ser usado simplesmente como ferramenta para tornar "digital" o status quo da sociedade, mas, sim, como maneira de o Estado intervir nessa realidade para transformála, o que no Brasil significa, por exemplo, prestação mais eqüitativa de serviços públicos por meio dos canais eletrônicos. Governo eletrônico é, portanto, um meio para que a mudança ocorra, e não a própria essência das transformações impostas aos governos pela sociedade da informação.

Assim como foi ressalvado anteriormente com relação ao potencial de emprego do e-gov na reforma administrativa, é 
provável, contudo, que as conclusões aqui expressas apenas tangenciem as reais contribuições do governo eletrônico para o incremento das condições de governança, pois, conforme argumenta Nye Jr. (1999, p. 14), "nós estamos apenas nos primeiros estágios da revolução da informação".

Especificamente para o caso da política no Brasil, há indicativos de que a governança seja incrementada com a conti- nuidade da implementação de ações de e-governo. Embora tenha sido amplamente reconhecido esse potencial das TICs, a política de governo eletrônico ainda não se encontra inserida com a devida ênfase na agenda governamental brasileira, especialmente no campo político, de modo a contribuir decisivamente para a modernização do aparelho estatal.

(Artigo recebido em janeiro de 2005. Versão final em dezembro de 2005)

\section{Referências bibliográficas}

BARZELAY, Michael. The New Public Management: a bibliographical essay for Latin American (and other) scholars. International Public Management Journal, n. 3, p. 229-265, 2000.

. The New Public Management. improving research and policy dialogue.

Los Angeles: University of California Press, 2001.

Brasil. Presidência da República, Ministério da Administração Federal e Reforma do Estado (Mare), Câmara da Reforma do Estado. Plano diretor da reforma do aparelho do Estado. Brasília: 1995.

- Ministério do Planejamento, Orçamento e Gestão, Grupo de Trabalho

"Novas Formas Eletrônicas de Interação". Proposta de política de governo eletrônico para o Poder Executivo federal. Brasília: 2000.

- Casa Civil da Presidência da República, Ministério do Planejamento, Orçamento e Gestão (MPOG), Secretaria Executiva do Comitê Executivo do Governo Eletrônico (Cege). Dois anos de governo eletrônico - balanço preliminar. Brasília: 2002.

. Casa Civil da Presidência da República, Ministério do Planejamento, Orçamento e Gestão (MPOG), Secretaria Executiva do Comitê Executivo do Governo Eletrônico (Cege). Dois anos de governo eletrônico - balanço de realizações e desafios futuros. Brasilia: 2002.

Bresser Pereira, Luiz Carlos. Gestão do setor público: estratégia e estrutura para um novo Estado. In: Bresser Pereira, Luiz Carlos; SPINK, Peter (Orgs.). Reforma do Estado e administração pública gerencial. Rio de Janeiro: Fundação Getúlio Vargas, 1998. p. 21-38.

Fernandes, Ciro Campos C. Governo eletrônico e transformação da administração pública. In: CHAHIN, Ali et al. E-gov.br - A próxima revolução brasileira - eficiência, qualidade e democracia: o governo eletrônico no Brasil e no mundo. São Paulo: Prentice Hall, 2004. p. 102-108.

FountAIN, Jane E. Building the virtual State: information technology and institutional change. Washington: Brookings Institution Press, 2001. 
Frey, Klaus. Políticas públicas: um debate conceitual e reflexões referentes à prática da análise de políticas públicas no Brasil. Planejamento e Políticas Públicas, Brasília, n. 21, p. 211 259, 2000.

Grande, J. Ignacio C.; Araújo, María C.; Serna, Miquel S. La necesidad de teoría(s) sobre gobierno electrónico: una propuesta integradora. In: CONCURSO DE ENSAYOS Y Monografías del Clad sobre Reforma del Estado y Modernización de la Administración Pública, 16., 2002, Caracas. Anais eletrônicos... Caracas: Centro Latinoamericano de Administración para el Desarollo (CLAD), 2002.

HeEks, Richard. Reinventing government in the information age. In: (Ed.). Reinventing government in the information age: international practice in IT-enabled public sector reform. Londres: Routledge, 2002. p. 9-21.

HeEks, Richard; Bhatnagar, Subhash. Understanding success and failure in information age reform. In: HeEks, Richard (Ed.). Reinventing government in the information age: international practice in IT-enabled public sector reform. Londres: Routledge, 2002. p. 49-74.

Intosal. Auditing e-government. Viena: Intosai, Standing Committee on IT Audit, Task Force for Auditing E-Government, 2003. (International Organization of Supreme Audit Institutions)

Lane, Jan-Erik. New Public Management. Londres: Routledge, 2000.

Melo, Marcus A. Governance e reforma do Estado: o paradigma agente x principal. Revista do Serviço Público, Brasília, ano 47, n. 1, p. 67-82, jan./abr. 1996.

NAÇÕES UnidAs. Benchmarking e-government: a global perspective. Nova York: United Nations, American Society for Public Administration, 2002.

National Audit Office. Better public services through e-government. Londres: The Stationery Office, 2002.

. Better public services through e-government. Londres: The Stationery Office, 2002. (Artigo acadêmico sobre "Barreiras Culturais ao Governo Eletrônico" preparado por Helen Margetts [University College London] e Patrick Dunleavy [LSE] em suporte ao relatório do National Office Audit [2002a])

NyE JR., Joseph S. Information technology and democratic governance. In: KAMARCK, Elaine C.; Nye JR., Joseph (Eds.). Democracy.com? Governance in a networked world. Hollis: Hollis, 1999. p. 1-18.

OCDE. E-government: analysis framework and methodology. Paris: Organização para Cooperação e Desenvolvimento Econômico (OCDE), 2001.

Окот-Uма, Rogers. Electronic governance: re-inventing good governance. Londres: Commonwealth Secretariat London, 2001.

Souza, Mauro Castro L. de. Política de tecnologia da informação no Brasil-caminho para o século XXI. Brasília: NTC, 2002. 


\section{Resumo - Resumen - Abstract}

\section{Contribuições do governo eletrônico para a reforma administrativa e a governança no Brasil \\ Paulo Henrique Ramos Medeiros e Tomás de Aquino Guimarães}

$\mathrm{O}$ artigo investiga as contribuições da política de governo eletrônico para a reforma administrativa e a governança no Brasil. A pesquisa baseou-se na opinião de informantes-chave dos quatro setores que atuam no e-gov: setor público, iniciativa privada, terceiro setor e academia. Concluiu-se que as tecnologias de informação e comunicação (TIC) podem ser a principal ferramenta para as iniciativas de modernização do Estado, sendo ressalvado que o e-governo não pode ser visto como panacéia para as reformas: o uso de tecnologias deveria caminhar em paralelo com outras medidas governamentais, nos campos político e econômico, por exemplo. Embora tenha sido reconhecido o potencial das TIC, o governo eletrônico ainda não se encontra inserido com a ênfase necessária na agenda governamental brasileira, de modo a contribuir decisivamente para a reforma administrativa e a governança.

Palavras-chave: governo eletrônico; reforma administrativa; governança.

\section{Contribuciones de la política de gobierno electrónico para la reforma administrativa y la gobernanza en Brasil}

Paulo Henrique Ramos Medeiros y Tomás de Aquino Guimarães

$\mathrm{El}$ artículo investiga las contribuciones de la política de gobierno electrónico para la reforma administrativa y la gobernanza en Brasil. La investigación se basó en la opinión de informantes clave de los cuatro sectores que actúan en el e-gov: sector público, sector privado, tercer sector y la academia. Se concluyó que las tecnologías de información y comunicación (TIC) pueden ser la principal herramienta para las iniciativas de modernización del Estado, con la salvedad de que el e-gobierno no es una panacea para las reformas: el uso de tecnologías debería caminar en paralelo a otras medidas gubernamentales, en los campos político y económico, por ejemplo. Aunque haya sido reconocido el potencial de las TIC, el gobierno electrónico todavía no se encuentra insertado con el énfasis necesario en la agenda gubernamental brasileña de modo a contribuir decisivamente a la reforma administrativa y a la gobernanza.

Palabras clave: gobierno electrónico; reforma administrativa; gobernanza.

\section{Contributions of electronic government for administrative reform and governance in Brazil}

Paulo Henrique Ramos Medeiros and Tomás de Aquino Guimarães

The article explores the contributions of electronic government's policy for administrative reform and governance in Brazil. The research was based on the opinion of key stakeholders from the four sectors that constitute the e-gov: the public sector, the private sector, the third sector and the academic community. This paper concludes by suggesting that information and communication technologies (ICT) may be a key tool for the state modernization initiatives, noting, however, that e-government cannot be seen as a panacea for the reforms: technologies should be employed in parallel with other governmental measures, in the fields of politics and economy, for instance. Notwithstanding the recognition of the potential of ICT, electronic government is still not inserted with the necessary emphasis in the Brazilian governmental agenda to contribute in a decisive way for the administrative reform and governance.

Key words: electronic government; administrative reform; governance. 
Paulo Henrique Ramos Medeiros

Analista de Controle Externo do Tribunal de Contas da União e mestre em Administração pela UnB. Contato: paulohr@tcu.gov.br.

Tomás de Aquino Guimarães

Professor do Programa de Pós-Graduação em Administração da UnB e doutor em Sociologia pela USP. Contato: tomas@unb.br. 